\title{
Corporate Social Responsibility and Product Differentiation
}

\author{
Modhurima Dey Amin \\ Texas Tech University
}

\author{
Syed Badruddoza \\ Texas Tech University \\ Robert Rosenman \\ Washington State University
}

We explore how the source of motivations for Corporate Social Responsibility (CSR) affects market outcomes. The first source is consumer-led; firms practice CSR because consumers value it. If one firm practices CSR it achieves a competitive advantage. If all firms practice CSR, market shares and price remain similar but profits fall, resulting in a Prisoner's Dilemma. The other source is firm-led CSR that also generates prices, market shares, and revenue that are the same as when neither firms nor consumers care about CSR case, but firms allocate profit to equilibrate its marginal valuation of CSR and financial reward to owners.

Keywords: corporate social responsibility, product differentiation, hotelling model

\section{INTRODUCTION}

Corporate Social Responsibility (CSR) refers to firms taking actions in ways that enhance social, environmental, or other norms in the eyes of customers, owners, or other stakeholders (Shocker and Sethi, 1973; Carroll, 1991; Bénabou and Tirole, 2010). Firms may go beyond legal requirements in adopting progressive human resource management programs, developing non-animal testing procedures, or recycling production waste. Approximately one in $10 \mathrm{~S} \& \mathrm{P} 100$ companies provide a detailed account of CSR activities (Baskin and Gordon, 2005; Kotler and Lee, 2008) often because shareholders or consumers, seek information about the social reputation of companies (Environics International, 1999; Mintel, 2015; Dilts, 2019; Wall Street Journal, 2021). About 53\% of general American consumers see a company's social reputation as a determinant of their purchase decision (Harris Poll, 2019).

At issue is how CSR affects market outcomes. Peloza (2009) and Cavazotte and Chang (2016) point out that sampling limitations, variable interactions, diversity of CSR measures, and obscurity in regards to the direction of causality result in inconsistent findings in the empirical literature (Margolis and Elfenbein, 2007; Margolis et al., 2007). The most common ambiguity with the concept is to identify who gains from CSR (McWilliams et al., 2006). The motivation for CSR is unclear; CSR may be in a competitive attempt to increase market share and profitability (Heinkel et al., 2001) or it may be motivated by the social consciousness of a firm's owner or other stakeholders (e.g., Cutter, 2021). 
A number of studies support the idea that firms practice CSR as a way to compete for socially responsible consumers to raise profits (Friedman, 1962; Baron, 2001; McWilliams and Siegel, 2001). Under this interpretation, CSR offers an additional dimension of product differentiation to gain a competitive advantage (e.g., Creyer, 1997; Jensen, 2002; De Pelsmacker et al., 2005; Siegel and Vitaliano, 2007; Ailawadi et al., 2011; Kitzmueller and Shimshack, 2012). CSR is often characterized as the private provision (by firms) of public goods (Bagnoli and Watts, 2003; Besley and Ghatak, 2007). Firms producing final consumer goods are more likely to participate in voluntary environmental management systems which supports this conjecture (Innes and Sam, 2008).

When CSR is motivated by profit, however, firms practicing it should do better, on average, than those that don't, especially if the profit motivation builds on consumer valuation of CSR (Arora and Gangopadhyay, 1995; Besley and Ghatak, 2007). Empirical studies find mixed or no association between CSR and corporate returns (Orlitzky et al., 2003; Heal, 2005; Margolis and Elfenbein, 2008; Reinhardt et al., 2008). Studies that observe the impact of socially (ir)responsible acts on financial returns also find mixed evidence (e.g., Posnikoff, 1997; Wright and Ferris, 1997). Since the return to CSR is a long-term process and unlikely to be captured in short-run data on profitability, many other studies examine the nature of the relationship between some indicator of corporate social performance and long-term firm performance, again finding mixed evidence (e.g., McGuire et al., 1988; Waddock and Graves, 1997; Flammer, 2013; 2015).

If CSR is not profit-seeking, some other explanation is needed. Friedman (1970) argues that CSR may serve managers' utility. McWilliams and Siegel (2001) identify socially responsible attitudes on the part of managers or employees. Or it may be driven by other stakeholders (Porter and Kramer, 2006) even when CSR is not a part of company strategy, does not directly affect the current consumers of the product or consumers care very little about it. We term this "firm-led" CSR. The empirical literature (cited above) that finds no profit gain (or even lower profits) to firms practicing CSR supports firm preferences as a motivation for CSR.

In this paper, we use a two-dimensional variant of Irmen and Thisse's (1998) product differentiation model to explore how CSR impacts market outcomes with both consumer-led CSR and firm-led CSR. In the first case, consumers receive direct utility from CSR. They observe the rate of CSR practiced by the different firms in the market when making decisions about which firm to buy from. In the second case, firm owners exercise CSR for their own satisfaction, while consumers do not receive any direct utility. We also discuss how the market is affected when both motivations are present.

Key findings of the present study are the following. When consumers care about CSR it offers the possibility of increasing profit by using CSR as another way to differentiate. If only one firm seizes the opportunity, it increases that firm's own price and market share at the expense of its rival's price and market share. If both firms engage in profit-seeking CSR, it leads to lower profit - CSR becomes a cost of competition with no gain to the firms. Firm-led CSR does not impact price or market shares (they are the same as they would be in the competitive no CSR case). When CSR is firm-led, it takes a share of "profit" as CSR-motivated utility. When firm and consumers both value CSR, there is less than perfect substitutability between their valuations.

\section{MODEL OF FIRM COMPETITION, PRODUCT DIFFERENTIATION AND CSR}

Without loss of generality, we assume a two-dimensional Hotelling model where consumers are uniformly distributed, by their preferences for product characteristics, over a unit square $[0,1]^{2}$. Irmen and Thisse showed that in multi-dimensioned spaces firms differentiate only on one key characteristic. A twodimensioned market is sufficient to see if that important conclusion still holds when firms practice CSR, and if CSR affects primary differentiation. Each coordinate $\left(z_{1}, z_{2}\right)$ on the square represents a combination of characteristics preferred by the consumer at that location. Demand is completely inelastic so each consumer purchases one unit from one of the firms. Two firms, A and B, produce the good, differentiated only by the product characteristics the firm chooses. Hence, firm A chooses characteristics for its product that match only one location on the unit square. Firm B does likewise. The product characteristics are thus 
shown by the pair $a=\left(a_{1}, a_{2}\right)$ for firm $\mathrm{A}$, and by $b=\left(b_{1}, b_{2}\right)$ by firm $\mathrm{B}$. The marginal cost of production is constant, normalized to zero, and unaffected by the firm's choice of product characteristics. In addition, each firm may choose to spend some share of its revenue, denoted as $c_{i}, i \in\{A, B\}$, to further some social goal that brings no direct return to the company. We term this spending CSR.

The consumer in location $\left(z_{1}, z_{2}\right)$ buys from firm $A$ and receives a net utility of,

$u_{A}\left(z_{1}, z_{2}\right)=s+\gamma c_{A}-p_{A}-t_{1}\left(z_{1}-a_{1}\right)^{2}-t_{2}\left(z_{2}-a_{2}\right)^{2}$

where $s>0$ denotes a surplus such that the utility is nonnegative for any purchase, $c_{A} \in[0,1]$ is an indicator of CSR performed by firm $\mathrm{A}$, and $p_{A}$ is the price of the product paid to firm A. We interpret $1 \geq c_{A} \geq 0$ as the fraction of revenue invested in CSR by firm A. Many firms advertise X\% of all sales are donated to charity or $\$ Y$ is donated for each unit sold. For example, AmazonSmile.com-a version of the online retailer Amazon.com-promises to donate $0.5 \%$ of eligible purchases to the charitable organization of buyer's choice (AmazonSmile 2020). Consumers observe the portion of firm's profit invested in CSR and derive utility from it in the amount $\gamma c_{A}$ where $\gamma \geq 0$. Consumer utility increases only from the CSR spending by the firm the consumer buys from, because of a preference for aligning with a firm "doing good". Utility is based on percent of revenue because at time of purchase consumers usually do not have information on the total firm CSR contribution, and when firms tout their CSR, it is on this form. In addition, consumers care about other characteristics of the product they buy and lose utility proportional to the square of the distance of the product characteristics from their preferred location. The coefficients $t_{1}, t_{2}$ define how important each characteristic is to consumers. Following Irmen and Thisse (1998), $t_{2}>t_{1} \geq 0$ so characteristic 2 is termed "dominant." Analogously, if the consumer chooses to buy from firm B she receives a net utility,

$u_{B}\left(z_{1}, z_{2}\right)=s+\gamma c_{B}-p_{B}-t_{1}\left(z_{1}-b_{1}\right)^{2}-t_{2}\left(z_{2}-b_{2}\right)^{2}$

where, $c_{B} \in[0,1]$ is the rate of CSR conducted by firm $\mathrm{B}$, and $p_{B}$ is the price of its product. If $\gamma=0$, consumers do not care about CSR.

We also specify a firm objective function that allows for it to derive value from profit and CSR directly. Firm $i$ 's net value in the market is

$\Pi_{i}=u\left(c_{i} R_{i}\right)+\left(1-c_{i}\right)\left(R_{i}\right) \quad i \in\{A, B\}$

where, $\Pi_{i}$ represents the total value the firm receives with $p_{-i} D_{i}\left(p_{i}\right.$ and $D_{i}$ being, respectively, the price the firm charges and its demand) and $u\left(c_{i} R_{i}\right)$ denotes firm's monotonically increasing strictly concave utility from the share of revenue spent on CSR which equals $c_{i} R_{i}$ for $c_{i} \in[0,1]$. The motivation for this term may come from the owners (stockholders), management, or employees (e.g., Dilts 2019; Sonnenfeld 2021). The term represents firm-led CSR that is not directly tied with the firm's product, so a consumer does not directly observe the part of the price going to CSR or receive utility from it. An example is Microsoft's initiative of preserving the languages of indigenous communities in New Zealand (Microsoft, 2020). If the firm derives no intrinsic value from CSR, $u\left(c_{i} R_{i}\right) \equiv 0$ always and any investment therein is completely driven by the profit motive. We assume zero production costs so the revenue remaining after CSR is equivalent to the firm's profit. The above framework reduces to two-dimensional Irmen and Thisse model when $u\left(c_{i} R_{i}\right) \equiv 0$ and $\gamma=0$.

\section{EQUILIBRIUM ANALYSIS}

The game has four stages. Firms choose product locations simultaneously and independently at the first stage, then select the rate of investment in CSR at the second stage. CSR is chosen before market outcomes to allow it to be a strategic part of firm behavior, equivalent, in a sense, to product characteristics. Firms choose prices at the third stage. At the fourth stage, consumers choose which firm to buy from by observing 
the bundles of prices, rates of CSR, and product characteristics offered. We solve the model by applying backward induction.

Initially, we allow both consumers and firms to derive value from CSR. Hence in the consumer demand equation $\gamma>0$ and $u\left(c_{i} R_{i}\right) \geq 0, i \in\{A, B\}$.

\section{Fourth Stage}

Consumers purchase a unit from the firm that gives more utility according to their preferred location. The indifferent (marginal) consumer gets equal utility from purchasing from either firm A or B, so

$s+\gamma c_{A}-p_{A}-t_{1}\left(z_{1}-a_{1}\right)^{2}-t_{2}\left(z_{2}-a_{2}\right)^{2}$

$=s+\gamma c_{B}-p_{B}-t_{1}\left(z_{1}-b_{1}\right)^{2}-t_{2}\left(z_{2}-b_{2}\right)^{2}$

which means the characteristics of the two firm's product relate by

$\hat{Z}_{2}=\frac{\left(c_{A}-c_{B}\right) \gamma+\left(p_{B}-p_{A}\right)+t_{1}\left(b_{1}^{2}-a_{1}^{2}\right)+t_{2}\left(b_{2}^{2}-a_{2}^{2}\right)}{2 t_{2}\left(b_{2}-a_{2}\right)}-\frac{t_{1}\left(b_{1}-a_{1}\right)}{t_{2}\left(b_{2}-a_{2}\right)} z_{1}$.

Market demand for product A is thus (Irmen and Thisse, 1998),

$D_{A}=\int_{0}^{1} \int_{0}^{\hat{z}_{2}} d z_{2} d z_{1}$

$=\frac{\left(c_{A}-c_{B}\right) \gamma+\left(p_{B}-p_{A}\right)-\left(b_{1}-a_{1}\right)\left(1-b_{1}-a_{1}\right) t_{1}+\left(b_{2}^{2}-a_{2}^{2}\right) t_{2}}{2\left(b_{2}-a_{2}\right) t_{2}}$

Demand for product $\mathrm{B}$ is, $D_{B}=1-D_{A}$. Following Irmen and Thisse, we assume $b_{2} \geq a_{2}$ and $s$ is sufficiently large to ensure nonnegative consumer surplus. This last assumption makes total demand perfectly inelastic. The first assumption ensures that firm B locates above firm A on the vertical axis.

\section{Third Stage}

Anticipating consumer demand, every firm $i$ chooses is price, $p_{i}$, to maximize $\Pi_{i}$. After taking derivatives of the objectives with respect to prices and setting equal to zero we find the best response functions:

$$
\begin{aligned}
& p_{A}\left(p_{B}\right)=\frac{1}{2}\left[\gamma\left(c_{A}-c_{B}\right)+p_{B}+\left(b_{1}-a_{1}\right)\left(b_{1}+a_{1}-1\right) t_{1}+\left(b_{2}^{2}-a_{2}^{2}\right) t_{2}\right] \\
& p_{B}\left(p_{A}\right)=\frac{1}{2}\left[\gamma\left(c_{B}-c_{A}\right)+p_{A}+\left(b_{1}-a_{1}\right)\left(1-b_{1}-a_{1}\right) t_{1}-\left(b_{2}^{2}-a_{2}^{2}\right) t_{2}\right]
\end{aligned}
$$

Prices increase in rival firm's price, increase in own rate of CSR, and decrease in rival's CSR rate. Assuming a firm's rate of CSR exceeds its competitor's, prices also increase with $\gamma$, the value consumers place on CSR. However, prices are independent of any utility a firm might derive from CSR.

Simultaneously solve the two equations above to obtain reduced forms of prices.

$$
\begin{aligned}
& p_{A}^{*}=\frac{1}{3}\left[\gamma\left(c_{A}-c_{B}\right)-\left(b_{1}-a_{1}\right)\left(b_{1}+a_{1}-1\right) t_{1}+\left(b_{2}-a_{2}\right)\left(2+a_{2}+b_{2}\right) t_{2}\right] \\
& p_{B}^{*}=\frac{1}{3}\left[\gamma\left(c_{B}-c_{A}\right)+\left(b_{1}-a_{1}\right)\left(b_{1}+a_{1}-1\right) t_{1}+\left(b_{2}-a_{2}\right)\left(4-b_{2}-a_{2}\right) t_{2}\right]
\end{aligned}
$$

The equilibrium prices lead to the following Lemma.

Lemma 1: Given consumers care about CSR $(\gamma>0)$, each firm's market share increases in its own CSR but decreases in rival's CSR. 
Proof: From the equilibrium prices we see $\frac{\partial p_{A}^{*}}{\partial c_{A}}=\frac{\partial p_{B}^{*}}{\partial c_{B}}=\frac{\gamma}{3} \geq 0, \frac{\partial p_{A}^{*}}{\partial c_{B}}=\frac{\partial p_{B}^{*}}{\partial c_{A}}=-\frac{\gamma}{3} \leq 0$. Using the equations for prices found in stage 3 in demand equations and take derivative with respect to the $c_{i}$ yields

$\frac{\partial D_{A}^{*}}{\partial c_{A}}=\frac{\gamma}{6\left(b_{2}-a_{2}\right) t_{2}} \geq 0$, and $\frac{\partial D_{A}^{*}}{\partial c_{B}}=\frac{-\gamma}{6\left(b_{2}-a_{2}\right) t_{2}} \leq 0$

$\frac{\partial D_{B}^{*}}{\partial c_{B}}=\frac{\gamma}{6\left(b_{2}-a_{2}\right) t_{2}} \geq 0$, and $\frac{\partial D_{B}^{*}}{\partial c_{A}}=\frac{-\gamma}{6\left(b_{2}-a_{2}\right) t_{2}} \leq 0$

Given consumers care about CSR $(\gamma>0)$, each firm's market share increases in its own CSR but decreases in rival's CSR. Although investment in CSR is deducted from revenue, holding the competitor's CSR constant a greater rate of CSR results in a bigger consumer base.

\section{Second Stage}

Anticipating prices, firms choose CSR at the second stage. After inserting demand and optimal prices in the profit functions and taking derivatives of each firm's objective with respect to its own CSR, the first order conditions are,

$\frac{\partial \Pi_{i}}{\partial c_{i}}=\left(\frac{\partial u\left(c_{i} R_{i}\right)}{\partial c_{i} R_{i}} c_{i}+1-c_{i}\right) \frac{\partial R_{i}}{\partial c_{i}}+\left[\frac{\partial u\left(c_{i} R_{i}\right)}{\partial c_{i} R_{i}}-1\right] R_{i}=0 \quad i \in\{A, B\}$

where, prices and demands, and thus revenue, are the functions of CSR derived above.

We explore three cases. Case 1 is consumer-led CSR, where consumers receive utility from CSR but firm owners do not; $\gamma>0, u\left(c_{i} R_{i}\right) \equiv 0$. Case 2 is firm-only led CSR, which requires $\gamma=0$ but allows for $u\left(c_{i} R_{i}\right) \geq 0$. Case 3 has both consumers and firms to value CSR so $\gamma>0, u\left(c_{i} R_{i}\right) \geq 0$.

\section{Case 1: Consumer-Led CSR}

Using the fact that $u\left(c_{i} R_{i}\right) \equiv 0$ the firms' first-order condition reduces to $\frac{\partial \Pi_{i}}{\partial c_{i}}=\left(1-c_{i}\right) \frac{\partial R_{i}}{\partial c_{i}}-R_{i}=$ $0 i \in\{A, B\}$. Substituting for prices and demands (derived above) and solving the choice of each firm simultaneously gives,

$c_{A}^{*}=\frac{1}{4 \gamma}\left[4 \gamma+\left(b_{1}-a_{1}\right)\left(1-b_{1}-a_{1}\right) t_{1}-\left(b_{2}-a_{2}\right)\left(5+a_{2}+b_{2}\right) t_{2}\right]$

$c_{B}^{*}=\frac{1}{4 \gamma}\left[4 \gamma-\left(b_{1}-a_{1}\right)\left(1-b_{1}-a_{1}\right) t_{1}-\left(b_{2}-a_{2}\right)\left(7-a_{2}-b_{2}\right) t_{2}\right]$

where, the optimal rates of CSR depend on consumers' valuation of the CSR, location choices, and transportation costs.

\section{Optimal Location Choices}

Using the optimal prices and CSR choices in $\Pi_{A}$ and $\Pi_{B}$ and deriving the first order conditions,

$$
\begin{aligned}
& \frac{\partial \Pi_{A}}{\partial a_{1}}=\frac{\left(2 a_{1}-1\right) t_{1}\left[\left(b_{1}-a_{1}\right)\left(1-b_{1}-a_{1}\right) t_{1}-\left(b_{2}-a_{2}\right)\left(5+a_{2}+b_{2}\right) t_{2}\right]^{2}}{96 \gamma\left(a_{2}-b_{2}\right) t_{2}}=0 \\
& \Rightarrow a_{1}^{*}=\frac{1}{2} \\
& \frac{\partial \Pi_{B}}{\partial b_{1}}=\frac{\left(2 b_{1}-1\right) t_{1}\left[\left(b_{1}-a_{1}\right)\left(1-b_{1}-a_{1}\right) t_{1}+\left(b_{2}-a_{2}\right)\left(7-a_{2}-b_{2}\right) t_{2}\right]^{2}}{96 \gamma\left(a_{2}-b_{2}\right) t_{2}}=0
\end{aligned}
$$


$\Rightarrow b_{1}^{*}=\frac{1}{2}$

and

$\frac{\partial \Pi_{A}}{\partial a_{2}}=\frac{\left(10+5 \mathrm{a}_{2}-\mathrm{b}_{2}\right)\left(\mathrm{a}_{2}-\mathrm{b}_{2}\right)\left(5+\mathrm{a}_{2}+\mathrm{b}_{2}\right)^{2} \mathrm{t}_{2}^{2}}{288 \gamma}=0$

$\Rightarrow a_{2}=\frac{b_{2}-10}{5}$

$\frac{\partial \Pi_{B}}{\partial b_{2}}=\frac{\left(14+\mathrm{a}_{2}-5 \mathrm{~b}_{2}\right)\left(\mathrm{a}_{2}-\mathrm{b}_{2}\right)\left(7-\mathrm{a}_{2}-\mathrm{b}_{2}\right)^{2} \mathrm{t}_{2}^{2}}{288 \gamma}=0$

$\Rightarrow b_{2}=\frac{14+a_{2}}{5}$

Solving simultaneously gives $a_{2}^{*}=-\frac{3}{2}$ and $b_{2}^{*}=\frac{5}{2}$, which implies, $a_{2}^{*}=0$ and $b_{2}^{*}=1$ because locations are constrained to be between 0 and 1. These are the same as found by Irmen and Thisse (1998). Consumer preference for CSR does not affect firms' choices for other product characteristics.

Lemma 2: Given consumers care about CSR $(\gamma>0)$, both $\mathrm{c}_{\mathrm{A}}^{*}, \mathrm{c}_{\mathrm{B}}^{*}$ are larger if $\mathrm{a}_{2} \rightarrow \mathrm{b}_{2}$. Moreover, $\mathrm{c}_{\mathrm{A}}^{*}, \mathrm{c}_{\mathrm{B}}^{*} \rightarrow$ $\infty$ when firms are profit-seeking $\left(u\left(c_{i} R_{i}\right)=0\right)$ and consumers do not care about CSR $(\gamma=0)$.

Proof: The Lemma holds because of the negative terms in the optimal CSR rates. Given $\gamma>0$, setting $a_{1}=$ $b_{2}=\frac{1}{2}$ makes the second term in equations (14) and (15) disappear, setting $a_{2}=0, b_{2}=1$ yield equal level of CSR, and setting $a_{2}=b_{2}$ increases the CSR rates. That is, the more firms look similar on the dominant characteristic, the higher their CSR rate. This is consistent with the literature that sees CSR as another dimension of product differentiation (e.g., Kitzmueller and Shimshack, 2012; Banerjee and Wathieu, 2017). Our model suggests that consumers must value the CSR for it to create product differentiation. No amount of CSR will maximize profit if consumers do not care for the cause.

Using these values to find optimal prices, market shares, profits, CSRs, and value functions gives

$p_{A}^{*}=p_{B}^{*}=t_{2}$

$D_{A}^{*}=D_{B}^{*}=\frac{1}{2}$

$p_{A}^{*} D_{A}^{*}=p_{B}^{*} D_{B}^{*}=\frac{t_{2}}{2}$

$c_{A}^{*}=c_{B}^{*}=1-\frac{3 t_{2}}{2 \gamma}$

$\Pi_{A}^{*}=\Pi_{B}^{*}=\left(1-c_{i}^{*}\right) \frac{t_{2}}{2}=\frac{3 t_{2}^{2}}{4 \gamma}$.

Notice that, CSR is positive if $\gamma>1.5 t_{2}$ (otherwise it is 0 ). This condition implies that consumer-led CSR only happens when consumers value CSR significantly more than the dominant characteristic of the product.

Given the equilibrium outcomes, the following observation can be made. 
Proposition 1: Assume firms are profit-seeking $\left(u\left(c_{i} R_{i}\right)=0\right)$ and consumers value CSR $(\gamma>0)$, then $\frac{\partial \mathrm{c}_{\mathrm{i}}^{*}}{\partial \gamma} \geq 0$ and $\frac{\partial \mathrm{c}_{\mathrm{i}}^{*}}{\partial \mathrm{t}_{2}}<0$. Most importantly, $\frac{\partial \Pi_{\mathrm{i}}^{*}}{\partial \mathrm{c}_{\mathrm{i}}^{*}}<0$.

Proof: If the CSR is motivated by consumer preferences and firms exploit that preference for profit-seeking, it becomes another means of competition. From the equilibrium outcomes above, $\frac{\partial c_{i}^{*}}{\partial \gamma}=\frac{3 t_{2}}{2 \gamma} \geq 0 \frac{\partial c_{i}^{*}}{\partial t_{2}}=$ $-\frac{3}{2 \gamma}<0$. The rate increases as consumer valuation increases, but decreases when the transportation cost of the dominant characteristic rises. Although firms compete and receive the same revenue as when there is no CSR (see Appendix), the firm's profit falls because a part of the revenue is spent on CSR, $\frac{\partial \Pi_{i}^{*}}{\partial c_{i}^{*}}=-\frac{t_{2}}{2} \leq$ 0 . Competition forces firms to devote a share of revenue to CSR (at the expense of profit), with the share larger the more consumers value it. In Irmen-Thisse $\mathrm{CSR}=0$ so the firm's profit (value function) $=\frac{t_{2}}{2}$. While both firms would be better off with no CSR, strong consumer interest in CSR motivates both firms to optimally use it as a competitive tool, resulting in less profit - a classic Prisoner's Dilemma.

\section{If the Government Sets CSR}

The above findings are based on when firms can choose respective CSR rates. A relevant question is, what happens when the rate is exogenously set, say, by the government. Can CSR be used as an instrument in public policy, e.g., environment preservation? For example, the Biden administration may require companies to address racial inequality, environmental damage, and other types of sustainability metrics (Glazer, 2021). A mixed method can be used, e.g., Bangladesh offers tax breaks to large companies on setting up hospitals in rural areas (Daily Star, 2021).

Corollary 1: Assume firms are profit-seeking and consumers value CSR, then a homogenous regulatory CSR is analogous to the competitive CSR.

Proof: Assume a case where consumers value CSR but firms do not, and policymakers externally define the lower limit of CSR such that both firms participate, $\bar{c}_{A}=\bar{c}_{B}=\bar{c}$. The utility from CSR cancels out from the indifferent consumer's decision. Profit maximization leads to the same location choices; $a_{1}^{*}=b_{1}^{*}=$ $\frac{1}{2} ; a_{2}^{*}=-\frac{1}{4} \rightarrow 0, b_{2}^{*}=\frac{5}{4} \rightarrow 1$, the same prices $p_{A}^{*}=p_{B}^{*}=t_{2}$, market shares $D_{A}^{*}=D_{B}^{*}=\frac{1}{2}$, hence the same revenues and profits. Thus, a regulated CSR is analogous to the competitive CSR when all firms are participating and consumers actually value CSR. If $c_{i}^{*}>\bar{c}$, competitive pressure will push both firms to the level of the competitive situation, i.e., so that $c_{A}^{*}=c_{B}^{*}=1-\frac{3 t_{2}}{2 \gamma}$. However, if $\bar{c}>1-\frac{3 t_{2}}{2 \gamma}$, we get the same outcome of location and revenue, but firms have lower net profit and consumers have a greater net utility than the competitive outcome. Government-mandated CSR beyond the competitive amount results in a redistribution from firms to consumers.

\section{If One Firm Offers CSR}

We so far assumed both firms optimally invest in CSR. This section explains why, in equilibrium, both firms will. Without loss of generality, assume $c_{B} \equiv 0$, so only firm A has the opportunity to invest in CSR. Perhaps it is a preemptive strategic move seeking a (short-run) advantage. Consumers' demand for firm A at the fourth stage becomes,

$D_{A}=\frac{c_{A} \gamma+p_{B}-p_{A}+\left(b_{1}-a_{1}\right)\left(b_{1}+a_{1}-1\right) t_{1}+\left(b_{2}^{2}-a_{2}^{2}\right) t_{2}}{2\left(b_{2}-a_{2}\right) t_{2}}$

$D_{B}=1-D_{A}$ 
Optimal prices in the third stage are

$$
\begin{aligned}
& p_{A}^{*}=\frac{1}{3}\left[\gamma c_{A}-\left(b_{1}-a_{1}\right)\left(b_{1}+a_{1}-1\right) t_{1}+\left(b_{2}-a_{2}\right)\left(2+a_{2}+b_{2}\right) t_{2}\right] \\
& p_{B}^{*}=\frac{1}{3}\left[\left(-\gamma c_{A}\right)+\left(b_{1}-a_{1}\right)\left(b_{1}+a_{1}-1\right) t_{1}+\left(b_{2}-a_{2}\right)\left(4-b_{2}-a_{2}\right) t_{2}\right]
\end{aligned}
$$

Using the optimal prices and simultaneously solving for $c_{A}$ gives

$$
c_{A}^{*}=\frac{2}{3}+\frac{1}{3 \gamma}\left[\left(a_{1}-b_{1}\right)\left(a_{1}+b_{1}-1\right) t_{1}-\left(b_{2}-a_{2}\right)\left(2+a_{2}+b_{2}\right) t_{2}\right] .
$$

Using the optimal prices and CSR choices in $\Pi_{A}$ and $\Pi_{B}$ and deriving the first order conditions, again gives

$$
\begin{aligned}
& \frac{\partial \Pi_{A}}{\partial a_{1}}=0 \Rightarrow a_{1}^{*}=\frac{1}{2} \\
& \frac{\partial \Pi_{B}}{\partial b_{1}}=0 \Rightarrow b_{1}^{*}=\frac{1}{2}
\end{aligned}
$$

Maximizing with respect to $a_{2}, b_{2}$ gives

$$
a_{2}^{*}=-1-\frac{\sqrt{t_{2}\left(16 \gamma+81 t_{2}\right)}}{4 t_{2}} \rightarrow 0, b_{2}^{*}=\frac{5}{4} \rightarrow 1
$$

Corollary 2: Assume firms are profit-seeking, and consumers value CSR, but one firm practices CSR and the other does not, i.e., $c_{A}>0, c_{B}=0$. Then profit of the firm that practices CSR increases and that of the firm that does not decrease.

Proof: Use the optimal locations in equilibrium outcomes to obtain,

$$
\begin{aligned}
& p_{A}^{*}=\frac{2}{9}\left(3 t_{2}+\gamma\right), p_{B}^{*}=\frac{2}{9}\left(6 t_{2}-\gamma\right) \\
& D_{A}^{*}=\frac{1}{3}+\frac{\gamma}{9 t_{2}}, D_{B}^{*}=\frac{2}{3}-\frac{\gamma}{9 t_{2}} \\
& p_{A}^{*} D_{A}^{*}=\frac{2\left(\gamma+3 t_{2}\right)^{2}}{81 t_{2}}, p_{B}^{*} D_{B}^{*}=\frac{2\left(\gamma-6 t_{2}\right)^{2}}{81 t_{2}} \\
& c_{A}^{*}=\frac{2}{3}-\frac{t_{2}}{\gamma}, \quad c_{B}^{*}=0 \\
& \Pi_{A}^{*}=\frac{2\left(\gamma+3 t_{2}\right)^{3}}{243 \gamma t_{2}}, \Pi_{B}^{*}=\frac{2\left(\gamma-6 t_{2}\right)^{2}}{81 t_{2}}
\end{aligned}
$$

Compare the results with the case of both firms offering CSR. Firm locations remain the same - they do not differentiate on the dominated characteristic and maximally differentiate on the dominant characteristic. But firm A charges more than firm B and has a larger market share when $\gamma \geq 1.5 t_{2}$. Given sufficient consumer preference for CSR, firm A uses it to increase its price and market share. If $\gamma \geq 6 t_{2}$ firm A has the entire market with $p_{A}=2 t_{2}$. If $\gamma<1.5 t_{2}, c_{A}=0$ and the result is as if consumers do not care about CSR. Notice this is the same condition needed for CSR when both firms used it. This brief analysis explains the root cause of the Prisoner's Dilemma outcome. When consumers care sufficiently about CSR, letting your opponent use it alone lowers your profit and cedes market share. 
This result explains the empirical works that find CSR improving profit (e.g., Flammer, 2013; 2015). Those studies have some, but not all, firms providing CSR, a situation analogous to the model we use in this section. However, this outcome is not a long-run equilibrium. Firm B would have an incentive to also start CSR, dissipating the gain Firm A has when the only CSR practitioner. In the long run, something rarely testable empirically, all firms would practice CSR and firm profits would be lower. In the short run CSR works as a way to differentiate a firm and improve its profit, but in the end, as shown by Irmen and Thisse, unless it is the primary characteristics, all firms will practice the same amount.

\section{Case 2: Firm-Led CSR}

If consumers don't care about CSR, $\frac{\partial R_{i}}{\partial c_{i}}=0$ so we have

$\frac{\partial \Pi_{i}}{\partial c_{i}}=\frac{\partial u\left(c_{i} R_{i}\right)}{\partial c_{i} R_{i}}\left(R_{i}\right)-R_{i}=0$

SO

$\Rightarrow\left[\frac{\partial u\left(c_{i} R_{i}\right)}{\partial c_{i} R_{i}}-1\right] R_{i}=0$

Hence $\frac{\partial u\left(c_{i} R_{i}\right)}{\partial c_{i} R_{i}}=1$. Firms invest in CSR until the value they get from it is the same as the value they get from another dollar of profit. Moreover, $\frac{\partial u\left(c_{i} R_{i}\right)}{\partial c_{i} R_{i}}=1 \Rightarrow \frac{\partial u\left(c_{i} R_{i}\right)}{\partial R_{i}}=\frac{\partial u\left(c_{i} R_{i}\right)}{\partial c_{i} R_{i}} \frac{\partial c_{i} R_{i}}{\partial R_{i}}=\frac{\partial c_{i} R_{i}}{\partial R_{i}}=c_{i}$. By the constraints on $c_{i}$ the marginal CSR utility of revenue is always positive. Revenue increases both profit and the utility from CSR, so more revenue is always desirable. And of course, $\frac{\partial \Pi_{i}}{\partial R_{i}}=c \frac{\partial u\left(c_{i} R_{i}\right)}{\partial R_{i}}+\left(1-c_{i}\right)>0$ always under our assumption that utility is monotonically increasing and $0 \leq c_{i} \leq 1$. In fact since $\frac{\partial u\left(c_{i} R_{i}\right)}{\partial c_{i} R_{i}}=$ $1 \Rightarrow \partial u\left(c_{i} R_{i}\right)=\partial c_{i} R_{i}$, we know that $\frac{\partial \Pi_{i}}{\partial R_{i}}=c_{i} \frac{\partial u\left(c_{i} R_{i}\right)}{\partial R_{i}}+\left(1-c_{i}\right)=c_{i} \frac{\partial c_{i} R_{i}}{\partial R_{i}}+\left(1-c_{i}\right)=c_{i}^{2}+\left(1-c_{i}\right)>$ 0 always by the constraints on $c_{i}$. Whatever share is given to CSR, firms will want revenue as large as possible, giving the competitive result of Irmen and Thisse, which means that the firms diverge as much as possible on the dominant characteristic and look alike on the dominated characteristic. As a result $a_{1}=$ $b_{1}=\frac{1}{2}, a_{2}=0, b_{2}=1$, and we have the following proposition.

Proposition 2: Assume consumers do not value CSR, $\frac{\partial R_{i}}{\partial c_{i}}=0$, but firms do, $u\left(c_{i} R_{i}\right) \neq 0$. Then aggregate utility in the economy is higher than the no-CSR case.

Proof: From the location values we get,

$p_{A}^{*}=p_{B}^{*}=t_{2}$

$D_{A}^{*}=D_{B}^{*}=\frac{1}{2}$

$p_{A}^{*} D_{A}^{*}=p_{B}^{*} D_{B}^{*}=\frac{t_{2}}{2}$

Without a specific functional form for $u\left(c_{i} R_{i}\right)$ we cannot find $c_{i}$ or $\Pi_{i}$, but market shares and competitive responses are the same. Firm-led CSR generates prices and profits similar to no CSR case (as shown in the Appendix), but firm owners maximize their value by contributing some of that value to CSR. Moreover, because $\frac{\partial u\left(c_{i} R_{i}\right)}{\partial c_{i} R_{i}}=1$ and the nature of $u\left(c_{i} R_{i}\right)$, the total value realized by the firm, $\Pi_{i}$, is greater than if the 
firm does no CSR. This, of course, is a tautology. Firm-led CSR is voluntary. A firm will only pursue CSR if it increases its total value.

\section{Case 3: Combination of Firm- and Consumer-Led CSR}

Proposition 3: Consumer-led and firm-led CSR are not necessarily substitutes.

Proof: As before $\frac{\partial \Pi_{i}}{\partial c_{i}}=\left(\frac{\partial u\left(c_{i} R_{i}\right)}{\partial c_{i} R_{i}} c_{i}+1-c_{i}\right) \frac{\partial R_{i}}{\partial c_{i}}+\left[\frac{\partial u\left(c_{i} R_{i}\right)}{\partial c_{i} R_{i}}-1\right] R_{i}=0 \quad i \in(A, B)$ implying $c_{i}=\frac{1}{1-\frac{\partial u\left(c_{i} R_{i}\right)}{\partial c_{i} R_{i}}}-\frac{R_{i}}{\frac{\partial R_{i}}{\partial c_{i}}}$.

We know $\frac{\partial R_{i}}{\partial c_{i}}>0$ (because CSR increases both price and demand) so if $\frac{\partial u\left(c_{i} R_{i}\right)}{\partial c_{i} R_{i}}>1$ then $c_{i}=0$ because it cannot be less than 0 . Hence, if both firm and consumers care and CSR is positive then $\frac{\partial u\left(c_{i} R_{i}\right)}{\partial c_{i} R_{i}}<$ 1 , that is, the firm's marginal utility from CSR is less than each dollar spent on CSR. Firms spend more on CSR than they would if consumers did not care about it, and in fact, more than they would on their own motivation. Looking at it from the consumer perspective, in a consumer-only CSR market (i.e., when $u\left(c_{i} R_{i}\right) \equiv 0$, we found from the firm's FOC that $c_{i}=1-\frac{R_{i}}{\frac{\partial R_{i}}{\partial c_{i}}}$ so CSR also exceeds what it is if firms do not value it. When both firms and consumers value CSR there is more of it than if only one side or the other does. Consumer-led and firm-led CSR are complements, not substitutes. If corporations worry about stakeholders other than shareholders, it does not necessarily hurt the economy; our results argue it is simply redistributive.

\section{SOME EXAMPLES}

"Dick's Sporting Goods" is one of the largest sellers of guns in the U.S. After the Florida school shooting in February 2018, the firm almost immediately raised the gun-buying age at its stores to 21 and ended its sales of assault-style rifles and high-capacity magazines. Dick's experienced a fall in gun sales and revenue while its competitors had growth. But Dick's actions appealed to socially aware consumers and the sales for higher-margin items like baseball gear and kayaks increased. The company reported a $4.6 \%$ growth in net sales in the first quarter of 2018, more than expected. The immediacy of Dick's actions suggests firm-led CSR, while the increase in net revenue from its socially aware action indicates consumers also cared. Consistent with what we showed above, (eventually) Walmart announced that it would stop selling ammunition for military-style assault rifles and all handgun ammunition-which may result in a 6\%-9\% drop in the share of its ammunition sales (Peterson, 2019).

An additional example is with vaping products. In 2015 CVS discontinued selling all tobacco products and vowed to never sell e-cigarettes. With additional news about the harm of vaping, Rite Aid and Walmart phased out e-cigarettes in 2019. These examples provide some anecdotal evidence that firms respond to competitive pressure following public sentiment favoring some specific types of CSR.

A final example of consumer-led CSR is in the fast-food industry. Except for differentiating on the primary characteristic (the food served), fast food chains have small variations, trying to match each other on speed and other ambiance-type characteristics. Recently three quick-service food chains with large shares of the quick breakfast market, McDonald's, Dunkin Donuts, and Taco Bell, announced a goal of using only cage-free eggs by the end of 2025 (Tristano, 2016). In a survey, $47 \%$ of consumers said they would like to order foods made from cage-free eggs or poultry but only $17 \%$ of those consumers were likely to pay more for it. Competition for customers will make it difficult to raise prices to cover the additional cost, but once one firm proposes CSR, the others follow. Cage-free eggs in the fast-food industry seems to illustrate the Prisoner's dilemma outcome for firms responding to CSR consumer preferences. 
There are examples of firm-led CSR as well. Recently, top U.S. CEOs have shown interest in devoting resources to providing amenities to communities that are not necessarily associated with their products or customers (Dilts, 2019; Sonnenfeld, 2021, Cutter, 2021;). Many of these actions are related to diversity, human rights, environmental sustainability, and economic welfare. Some of the actions are motivated by consumer interests or sustainability of the business, others serve firms' utility beyond profit. For example, Newman's Own brand of premium food products donates $100 \%$ of its profits to charity and in fact, was founded with that strategy. Ben and Jerry's ice cream was also founded with a socially conscious strategic goal, albeit not quite so generous as Newman's Own. For both food brands, prices are consistent with other premium brands that do not tout socially conscious behavior, indicating at least in these markets, consumers do not really value CSR and what we see is firm-led.

\section{CONCLUDING REMARKS}

We develop a product differentiation model that incorporates Corporate Social Responsibility (CSR) and hypothesize two sources of CSR - consumer-led and firm-led. Despite firms or consumers valuing CSR, product differentiation follows Irmen and Thisse's conclusion and does not change across the cases. Firms maximally differentiate along the dominant characteristic and minimally differentiate on other characteristics.

If consumers value CSR it offers another potential for differentiation. But competitive pressure pushes both firms to offer CSR at the same level and at their own expense. Prices, market shares, and revenues are the same as without CSR. The difference is that firms must devote part of the revenue to CSR, leaving lower profits. And the more consumers value CSR, the more firms spend on it, with nothing to show for it in the end. Consumer-led CSR creates a Prisoner's dilemma problem for firms. All would be better off not practicing CSR, but all have an incentive to violate any implicit or explicit agreement to not offer it. The long-run equilibrium is all firms practicing CSR, but with lower profits. Firm-led CSR also results in prices, market shares, and revenue the same as the no CSR case. Now, however, firms invest in CSR on their own volition and thus there is no value lost to the firm - in fact the total value the firm garners from the market is higher than if it didn't practice CSR. In the case where both firms and consumers value CSR, the total amount is more than when only one side or the other values it.

\section{REFERENCES}

Ailawadi, K.L., Luan, Y.J., Neslin, S.A., \& Taylor, G.A. (2011). The Impact of Retailers' Corporate Social Responsibility on Price Fairness Perceptions and Loyalty. Institut d 'economie industrielle. Retrieved September 23, 2019, from http://idei.fr/sites/default/files/medias/doc/conf/inra/2011/ailawadi\%20kusum.pdf

AmazonSmile. (2020). About AmazonSmile. Retrieved September 21, 2020, from https://smile.amazon.com/gp/chpf/about/ref=smi_se_dshb_lm_saas?ie=UTF8\&ref_=smi_se_mirp _dshb_smi

Arora, S., \& Gangopadhyay, S. (1995). Toward a theoretical model of voluntary overcompliance. Journal of Economic Behavior and Organization, 28(3), 289-309.

Bagnoli, M., \& Watts, S.G. (2003). Selling to socially responsible consumers: Competition and the private provision of public goods. Journal of Economics \& Management Strategy, 12(3), 419445.

Banerjee, S., \& Wathieu, L. (2017). Corporate social responsibility and product quality: Complements or substitutes? International Journal of Research in Marketing, 34(3), 734-745.

Baron, D.P. (2001). Private politics, corporate social responsibility, and integrated strategy. Journal of Economics \& Management Strategy, 10(1), 7-45.

Baskin, J., \& Gordon, K. (2005). Corporate responsibility practices of emerging market companies. OECD Working Papers on International Investment, 2005/03. OECD Publishing. http://dx.doi.org/10.1787/713775068163 
Bénabou, R., \& Tirole, J. (2010). Individual and corporate social responsibility. Economica, 77(305), 119.

Besley, T., \& Ghatak, M. (2007). Retailing public goods: The economics of corporate social responsibility. Journal of Public Economics, 91(9), 1645-1663.

Carroll, A.B. (1991). The pyramid of corporate social responsibility: Toward the moral management of organizational stakeholders. Business Horizons, 34(4), 39-48.

Cavazotte, F., \& Chang, N.C. (2016). Internal corporate social responsibility and performance: A study of publicly traded companies. Brazilian Administration Review, 13(4), e160083.

Creyer, E.H. (1997). The influence of firm behavior on purchase intention: Do consumers really care about business ethics? Journal of Consumer Marketing, 14(6), 421-432.

Cutter, C. (2021, April 14). Hundreds of companies, CEOs band together on voting access. Wall Street Journal. Retrieved June 20, 2021, from https://www.wsj.com/articles/hundreds-of-companiesband-together-on-voting-access-11618403134.

Daily Star. (2021, June 21). Tax break on setting up hospitals: Fiscal relief inadequate to attract investors. Retrieved June 30, 2021, from https://www.thedailystar.net/business/tax-andcustoms/news/fiscal-relief-inadequate-attract-investors-2114989

De Pelsmacker, P., Driesen, L., \& Rayp, G. (2005). Do consumers care about ethics? Willingness to pay for fair-trade coffee. Journal of Consumer Affairs, 39(2), 363-385.

Dilts, E. (2019, August 19). Top U.S. CEOs say companies should put social responsibility above profit. Reuters. Retrieved June 30, 2021, from https://www.reuters.com/article/us-jp-morgan-businessroundtable-idUSKCN1V91EK

Environics International. (1999). The Millennium Poll on Corporate Social Responsibility: Executive Brief. Toronto: Environics International.

Flammer, C. (2013). Corporate social responsibility and shareholder reaction: The environmental awareness of investors. Academy of Management Journal, 56(3), 758-781.

Flammer, C. (2015). Does corporate social responsibility lead to superior financial performance? A regression discontinuity approach. Management Science, 61(11), 2549-2568.

Friedman, M. (1962). Capitalism and Freedom. Chicago: University of Chicago Press.

Friedman, M. (1970). A Friedman doctrine: The social responsibility of business is to increase its profits. The New York Times Magazine, 13(1970), 32-33.

Glazer, E. (2021, January 18). Companies brace themselves for new ESG regulations under Biden. Wall Street Journal. Retrieved June 20, 2021, from https://www.wsj.com/articles/companies-bracethemselves-for-new-esg-regulations-under-biden-11610719200

Harris Poll. (2019). The 100 Most Visible Companies. New York: Harris Insights and Analytics. Retrieved May 28, 2019, from https://theharrispoll.com/the-harris-pollr-today-released-its-17thannual-reputation-quotientr-rqr-summary-report-revealing-corporate-reputation-ratings-for-the100-most-visible-companies-in-the-u-s-as-perceived-by/

Heal, G. (2005). Corporate social responsibility: An economic and financial framework. The Geneva Papers on Risk and Insurance-Issues and Practice, 30(3), 387-409.

Heinkel, R., Kraus, A., \& Zechner, J. (2001). The effect of green investment on corporate behavior. Journal of Financial and Quantitative Analysis, 36(4), 431-449.

Innes, R., \& Sam, A.G. (2008). Voluntary pollution reductions and the enforcement of environmental law: An empirical study of the 33/50 program. The Journal of Law and Economics, 51(2), 271-296.

Irmen, A., \& Thisse, J.F. (1998). Competition in multi-characteristics spaces: Hotelling was almost right. Journal of Economic Theory, 78(1), 76-102.

Jensen, M.C. (2002). Value maximization, stakeholder theory, and the corporate objective function. Business Ethics Quarterly, pp. 235-256.

Kitzmueller, M., \& Shimshack, J. (2012). Economic perspectives on corporate social responsibility. Journal of Economic Literature, 50(1), 51-84.

Kotler, P., \& Lee, N. (2008). Corporate Social Responsibility: Doing the Most Good for Your Company and Your Cause. New York: John Wiley \& Sons. 
Margolis, J.D., Elfenbein, H.A., \& Walsh, J.P. (2007). Does it pay to be good? A meta-analysis and redirection of research on the relationship between corporate social and financial performance. [Working Paper]. Harvard Business School, Boston, MA.

Margolis, J.D., \& Elfenbein, H.A. (2008). Do well by doing good? Don't count on it. Harvard Business Review, Social Responsibility, Special Issue on HBS Centennial, 86(1), 19.

McGuire, J.B., Sundgren, A., \& Schneeweis, T. (1988). Corporate social responsibility and firm financial performance. Academy of Management Journal, 31(4), 854-872.

McWilliams, A., \& Siegel, D. (2001). Corporate social responsibility: A theory of the firm perspective. Academy of Management Review, 26(1), 117-127.

McWilliams, A., Siegel, D.S., \& Wright, P.M. (2006). Corporate social responsibility: International perspectives. Rensselaer Working Papers in Economics 0604. SSRN 900834.

Microsoft Corporation. (2020). Reimagining a better future together: 2020 Microsoft Corporate social responsibility report (p.19). Retrieved April 1, 2021, from https://query.prod.cms.rt.microsoft.com/cms/api/am/binary/RE4JaGo

Mintel. (2015). The Ethical Consumer-U.S. London: Mintel Group Ltd.

Orlitzky, M., Schmidt, F.L., \& Rynes, S.L. (2003). Corporate social and financial performance: A metaanalysis. Organization Studies, 24(3), 403-441.

Peloza, J. (2009). The challenge of measuring financial impacts from investments in corporate social performance. Journal of Management, 35(6), 1518-1541.

Peterson, H. (2019, September 3). Walmart will bar shoppers from openly carrying guns in its stores and stop selling some ammunition in response to 2 deadly shootings. Business Insider. Retrieved September 22, 2019, from https://www.businessinsider.com/walmart-bans-open-carry-gunsstops-selling-some-ammunition-2019-9

Porter, M.E., \& Kramer, M.R. (2006). The link between competitive advantage and corporate social responsibility. Harvard Business Review, 84(12), 78-92.

Posnikoff, J.F. (1997). Disinvestment from South Africa: They did well by doing good. Contemporary Economic Policy, 15(1), 76-86.

Reinhardt, F.L., Stavins, R.N., \& Vietor, R.H. (2008). Corporate social responsibility through an economic lens. Review of Environmental Economics and Policy, 2(2), 219-239.

Shocker, A.D., \& Sethi, S.P. (1973). An approach to incorporating societal preferences in developing corporate action strategies. California Management Review, 15(4), 97-105.

Siegel, D.S., \& Vitaliano, D.F. (2007). An empirical analysis of the strategic use of corporate social responsibility. Journal of Economics \& Management Strategy, 16(3), 773-792.

Sonnenfeld, J. (2021, April 15). CEOs lead America's new great awakening. Wall Street Journal. Retrieved June 20, 2021, from https://www.wsj.com/articles/ceos-lead-americas-new-greatawakening-11618505076

Tristano, D. (2016). The Cost of Corporate Social Responsibility. Forbes Food and Agriculture. Retrieved December 28, 2018, from https://www.forbes.com/sites/darrentristano/2016/01/04/thecost-of-corporate-social-responsibility/\#76d3fd8a3728

Waddock, S.A., \& Graves, S.B. (1997). The corporate social performance-financial performance link. Strategic Management Journal, 18(4), 303-319.

Wall Street Journal. (2021, March 30). Top companies for social responsibility: Microsoft heads this list from the management top 250 ranking. Business. Retrieved June 20, 2021, from https://www.wsj.com/articles/top-companies-for-social-responsibility-11617137132

Wright, P., \& Ferris, S.P. (1997). Agency conflict and corporate strategy: The effect of divestment on corporate value. Strategic Management Journal, 18(1), 77-83. 


\section{APPENDIX}

Basic Model Without CSR $\left(c_{A}=c_{B}=\gamma=0\right)$

This section focuses on the benchmark case where both firms maximize profit functions without any CSR component. Utility function does not include any CSR rate as well. The indifferent consumer has the following utility,

$s-p_{A}-t_{1}\left(z_{1}-a_{1}\right)^{2}-t_{2}\left(z_{2}-a_{2}\right)^{2}=s-p_{B}-t_{1}\left(z_{1}-b_{1}\right)^{2}-t_{2}\left(z_{2}-b_{2}\right)^{2}$

express $z_{2}=\hat{z}_{2}$ in terms of other variables and integrate like before to obtain the demand function for product $\mathrm{A}$,

$D_{A}=\int_{0}^{1} \int_{0}^{\hat{z}_{2}} d z_{2} d z_{1}=\frac{p_{B}-p_{A}+\left(b_{1}-a_{1}\right)\left(b_{1}+a_{1}-1\right) t_{1}+\left(b_{2}^{2}-a_{2}^{2}\right) t_{2}}{2\left(b_{2}-a_{2}\right) t_{2}}$

And for product $\mathrm{B}$,

$D_{B}=1-D_{A}$

Both firms have simple zero cost profit functions now that do not contain CSR investment.

$$
\begin{aligned}
& \max _{p_{A}} \Pi_{\mathrm{A}}=p_{A} D_{A} \\
& \max _{p_{B}} \Pi_{B}=p_{B} D_{B}
\end{aligned}
$$

Differentiating profit functions with respective prices and solving simultaneously leads to,

$$
\begin{aligned}
& p_{A}^{*}=\frac{1}{3}\left[-\left(b_{1}-a_{1}\right)\left(1-b_{1}-a_{1}\right) t_{1}+\left(b_{2}-a_{2}\right)\left(2+b_{2}+a_{2}\right) t_{2}\right] \\
& p_{B}^{*}=\frac{1}{3}\left[\left(b_{1}-a_{1}\right)\left(1-b_{1}-a_{1}\right) t_{1}+\left(b_{2}-a_{2}\right)\left(4-b_{2}-a_{2}\right) t_{2}\right]
\end{aligned}
$$

Use the optimal prices in profit functions and maximize with respect to horizontal and vertical characteristics. From the first order condition, we get $a_{1}^{*}=b_{1}^{*}=0.5$ for horizontal characteristics, which is consistent to Irmen and Thisse. For the vertical characteristics we get two equations,

$a_{2}=\frac{1}{3}\left(b_{2}-2\right), b_{2}=\frac{4+a_{2}}{3}$

Simultaneously solving them gives $a_{2}^{*}=-\frac{1}{4} \rightarrow 0$, and $b_{2}^{*}=\frac{5}{4} \rightarrow 1$. The location choices do not differ from the cases with CSR in the market. Firms choose maximum differentiation on the vertical axis, but minimum on the horizontal axis, with or without CSR. Use the location choices to get optimal values of prices, demands, and profits.

$$
\begin{aligned}
& p_{A}^{*}=p_{B}^{*}=t_{2} \\
& D_{A}^{*}=D_{B}^{*}=\frac{1}{2} \\
& \mathrm{p}_{A}^{*} D_{A}^{*}=\mathrm{p}_{\mathrm{B}}^{*} \mathrm{D}_{B}^{*}=\frac{t_{2}}{2}
\end{aligned}
$$

Locations, prices, demands, and profits are the same as firm-led CSR, irrespective of one firm or both firms offering CSR. 